\title{
Male microchimerism in women with systemic sclerosis and healthy women who have never given birth to a son
}

\author{
N C Lambert, J M Pang, Z Yan, T D Erickson, A M Stevens, D E Furst, J L Nelson
}

Ann Rheum Dis 2005;64:845-848. doi: 10.1136/ard.2004.029314

See end of article for
authors' affiliations
$\ldots \ldots \ldots \ldots \ldots \ldots \ldots . . . .$.
Correspondence to:
Dr Nathalie Lambert,
INSERM U639, Faculté de
Médecine La Timone,
13005 Marseille, France;
nathalie.lambert@
medecine.univ-mrs.fr
Accepted
9 November 2004
Published Online First
18 November 2004

See end of article for

Correspondence to: Dr Nathalie Lambert NSERM U639, Faculté de 13005 Marseille, France; nathalie.lamber+@ cine.univ-mrs.fr ......................

\begin{abstract}
Background: Male DNA or cells are often used to measure microchimerism in a woman. In studies of autoimmune diseases male microchimerism is most often attributed to the previous birth of a son.

Objective: To determine the frequency of male microchimerism in healthy women or women with systemic sclerosis who had never given birth to a son.

Methods: Real time quantitative polymerase chain reaction targeting the $Y$ chromosome specific sequence DYS1 4 was employed to test DNA extracted from peripheral blood mononuclear cells of 26 women with systemic sclerosis and 23 healthy women who had never given birth to a son. Results are expressed as the genome equivalent number of male cells per million host cells (gEq/mil).

Results: Male DNA was found in 15\% of women with systemic sclerosis (range 0 to $23.7 \mathrm{gEq} / \mathrm{mil}$ ) and in $13 \%$ of healthy women (range 0 to $5.1 \mathrm{gEq} / \mathrm{mil}$ ). Although two women with male DNA had an induced abortion, most had no history of spontaneous or induced abortion (either systemic sclerosis or healthy). Conclusions: Microchimerism with male DNA can be found in the circulation of women who have never given birth to a son. Thus sources other than a male birth must be considered when male DNA is used to measure microchimerism. Although other studies are needed, there was no apparent difference in women with systemic sclerosis and healthy women. Possible sources of male DNA include unrecognised male pregnancy or unrecognised male twin, an older male sibling with transfer through the maternal circulation, or sexual intercourse alone.
\end{abstract}

\section{METHODS}

Study subjects

Twenty six women with systemic sclerosis and 23 healthy women were studied, none of whom had a history of a male birth. Women with systemic sclerosis were classified as having diffuse $(\mathrm{n}=19 ; 73 \%)$ or limited $(\mathrm{n}=7 ; 27 \%)$ systemic sclerosis, according to previous descriptions of subset classification in this disease. ${ }^{7}$ Among the 26 affected women, $58 \%(\mathrm{n}=15)$ were parous and $42 \%(\mathrm{n}=11)$ nulliparous; among the 23 healthy women, $52 \%(n=12)$ were parous and $48 \%(\mathrm{n}=11)$ nulliparous. Six of the nulliparous women with systemic sclerosis were also nulligravid, as were eight of the healthy women. Some women with systemic sclerosis and some healthy women had a history of spontaneous abortion and a few had a history of induced abortion, as shown in tables 1 and 2.

Study subjects came primarily from Seattle, Washington, USA and the surrounding areas. Eighty five per cent of women with systemic sclerosis were white, $4 \%$ Asian, and $11 \%$ of mixed ethnicity. Ninety five per cent of the healthy women were white, $0 \%$ Asian, and $4 \%$ of mixed ethnicity. Among women with systemic sclerosis, 24 had no history of blood transfusion (an alternative source of Mc) and for two the transfusion history was unknown. Eighteen healthy women had never received a blood transfusion, the transfusion history was unknown for four, and one had received a blood transfusion. One healthy woman had a male twin (HW-04). No woman with systemic sclerosis had a twin. All subjects provided informed consent.

Abbreviations: Mc, microchimerism; QPCR, quantitative polymerase chain reaction 
Table 1 Male DNA in women with systemic sclerosis who had never given birth to a son

\begin{tabular}{|c|c|c|c|c|c|c|c|c|}
\hline \multirow[b]{2}{*}{ Case } & \multirow[b]{2}{*}{ Age (years) } & \multirow[b]{2}{*}{ Disease } & \multirow{2}{*}{$\begin{array}{l}\text { Age at disease } \\
\text { onset (years) }\end{array}$} & \multirow[b]{2}{*}{ No of daughters } & \multicolumn{2}{|c|}{ No of fetal losses } & \multirow[b]{2}{*}{ Years from pregnancy* } & \multirow[b]{2}{*}{ Mc/million } \\
\hline & & & & & IA & SA & & \\
\hline SSc-01 & 52 & DIFF & 50 & 2 & 0 & 1 & 28.3 & 0 \\
\hline $\mathrm{SSc}-02$ & 46 & DIFF & 44 & 2 & 0 & 0 & 13.4 & 0 \\
\hline $\mathrm{SSc}-03$ & 49 & DIFF & 43 & 1 & uk & uk & 26.0 & 0 \\
\hline $\mathrm{SSc}-04$ & 50 & DIFF & 39 & 1 & 0 & 1 & 10.2 & 0 \\
\hline $\mathrm{SSc}-05$ & 37 & LIM & 26 & 1 & 0 & 2 & 14.0 & 0 \\
\hline SSc-06 & 31 & DIFF & 28 & 1 & 0 & 1 & 1.2 & 0 \\
\hline SSc-07 & 40 & DIFF & 34 & 1 & 1 & 0 & 8.9 & 3.9 \\
\hline SSc-08 & 19 & DIFF & 19 & 0 & 0 & 0 & na & 23.7 \\
\hline SSc-09 & 24 & DIFF & 7 & 0 & 0 & 0 & na & 0 \\
\hline $\mathrm{SSc}-10$ & 34 & DIFF & 33 & 0 & 0 & 0 & na & 2.0 \\
\hline SSc-11 & 36 & DIFF & 29 & 0 & 0 & 1 & 7.4 & 0 \\
\hline SSc-12 & 70 & DIFF & 45 & 2 & 0 & 1 & 40.9 & 0 \\
\hline SSc-13 & 40 & DIFF & 36 & 1 & 0 & 1 & 3.0 & 0 \\
\hline SSc-14 & 51 & LIM & 49 & 0 & 0 & 1 & 31.0 & 0 \\
\hline SSc- 15 & 47 & LIM & 38 & 0 & 0 & 0 & na & 0 \\
\hline SSc-16 & 47 & DIFF & 22 & 1 & 0 & 0 & 17.8 & 0.4 \\
\hline SSc-17 & 58 & LIM & 54 & 1 & 0 & 0 & 33.9 & 0 \\
\hline SSc-18 & 40 & DIFF & 38 & 2 & 0 & 0 & 14.0 & 0 \\
\hline SSc-19 & 51 & LIM & 44 & 1 & 0 & 2 & 8.7 & 0 \\
\hline SSc-20 & 49 & DIFF & 43 & 3 & 0 & 0 & 12.3 & 0 \\
\hline SSc-21 & 22 & DIFF & 20 & 0 & 0 & 0 & na & 0 \\
\hline SSc-22 & 51 & LIM & 49 & 0 & 1 & 0 & 31.0 & 0 \\
\hline SSc-23 & 46 & DIFF & 42 & 0 & 0 & 5 & uk & 0 \\
\hline SSc-24 & 53 & DIFF & 50 & 1 & 0 & 0 & 34.0 & 0 \\
\hline SSc-25 & 53 & LIM & 45 & 0 & 0 & 3 & 18.0 & 0 \\
\hline SSc-26 & 37 & DIFF & 35 & 0 & 0 & 0 & na & 0 \\
\hline
\end{tabular}

*Years from outcome of most recent pregnancy.

DIFF, diffuse systemic sclerosis; IA, induced abortion; LIM, limited systemic sclerosis; Mc, microchimerism; na, not applicable; SA, spontaneous abortion; uk, unknown.

\section{Isolation of peripheral blood mononuclear cells and DNA extraction}

Whole blood was drawn into acid citrate dextrose solution A vacutainer tubes and processed by Ficoll Hypaque centrifugation to isolate peripheral blood mononuclear cells (PBMC) (Pharmacia Biotech AB, Uppsula, Sweden). DNA was extracted from PBMC with a Promega Wizard kit (Promega, Madison, Wisconsin, USA) according to the manufacturer's instructions, and resuspended in water.

\section{DYS 14 real time quantitative $P C R$}

A real time quantitative PCR (QPCR) assay that we had previously developed and reported $^{8}$ was employed. This targets the Y chromosome specific sequence DYS14. Each DNA sample was tested in six to 12 aliquots of 5000 to 20000 genome equivalent cells for DYS14, with two similar aliquots tested for $\beta$ globin to define the total DNA concentration of the sample tested. The conversion factor used was $6.6 \mathrm{pg}$ of DNA per cell. Information was combined across aliquots of PBMC as described previously. ${ }^{8}$ For ease of expression the amount of male DNA was expressed as the number of genome equivalent male cells per million maternal cells (gEq/ mil). As a conservative estimate of the frequency of male DNA we further required that a sample show a result above threshold in a minimum of two different wells per assay, or be confirmed in a second test.

\section{Specificity of the DYS 14 assay}

As previously reported, the DYS14 sequence was found not to cross react with any other DNA sequence. ${ }^{8}$ In addition, in the current studies each experimental QPCR plate included the DNA equivalent of 10000 human nulligravid female cells systematically used as background with increased concentrations of $0,1,510,50,100,500$ equivalent DNA of male cells. Therefore in each plate a triplicate of 0 male DNA in 10000 female DNA was tested for male DNA amplification with a DYS14 PCR assay and was consistently negative. This provided an internal control indicating that the DYS14 QPCR assay does not cross react with other DNA sequences.

\section{Precautions to minimise contamination risk}

False positive results are always a concern with PCR based methods, and risk of contamination may be of special concern for assays that target male DNA. Multiple aspects of methods used in the current study were designed to minimise any potential contamination risk. The optical detection system of the 7000 Sequence Detector obviates the need to reopen reaction tubes after amplification. A female technician conducted all experiments including DNA extraction and the QPCR assays. DNA extractions and QPCR preparations were done under an ultraviolet (UV) light equipped safety hood, with UV run for 30 minutes between experiments to avoid persistence of any remaining DNA. Filtered tips were used in all pipetting. Additionally, each experiment included controls to monitor for possible contamination, and negative controls were always negative. In cases where samples were tested more than once, samples negative in a first experiment were also negative in a second test.

\section{RESULTS}

Microchimerism with male DNA in peripheral blood mononuclear cells was found in some women with systemic sclerosis and in healthy women with no history of previous birth of a son. Among women with systemic sclerosis, 15\% (4/26) had male DNA, and among healthy women 13\% (3/23) (tables 1 and 2). Fifty five per cent of all women were parous but had only given birth to daughters, representing $58 \%$ of women with systemic sclerosis $(n=15)$ and $52 \%$ of healthy women $(n=12)$. Among parous women with systemic sclerosis, two $(8 \%)$ had male DNA, and among healthy women none; one woman with systemic sclerosis had no other pregnancies and the other an induced abortion. Forty five per cent of all women were nulliparous, representing $42 \%$ of women with systemic sclerosis $(n=11)$ and $48 \%$ of 
Table 2 Male DNA in healthy women who had never given birth to a son

\begin{tabular}{|c|c|c|c|c|c|c|}
\hline \multirow[b]{2}{*}{ Case } & \multirow[b]{2}{*}{ Age (years) } & \multirow[b]{2}{*}{ No of daughters } & \multicolumn{2}{|c|}{ No of fetal losses } & \multirow[b]{2}{*}{ Years from pregnancy ${ }^{*}$} & \multirow[b]{2}{*}{ Mc/million } \\
\hline & & & IA & SA & & \\
\hline $\mathrm{HW}-01$ & 28 & 0 & 0 & 0 & $\mathrm{na}$ & 0 \\
\hline $\mathrm{HW}-02$ & 29 & 1 & 0 & 0 & 1.0 & 0 \\
\hline $\mathrm{HW}-03$ & 38 & 1 & 0 & 0 & 18.3 & 0 \\
\hline $\mathrm{HW}-04 \dagger$ & 41 & 2 & 0 & 1 & 2.5 & 0 \\
\hline HW-05 & 26 & 0 & 0 & 0 & na & 0 \\
\hline HW-06 & 35 & 1 & 0 & 0 & 2.5 & 0 \\
\hline HW-07 & 29 & 0 & 0 & 0 & na & 0.7 \\
\hline HW-08 & 50 & 1 & 0 & 0 & 30.2 & 0 \\
\hline HW-09 & 39 & 2 & 0 & 0 & 4.0 & 0 \\
\hline HW-10 & 30 & 0 & 0 & 0 & na & 5.1 \\
\hline HW-11 & 17 & 0 & uk & uk & $\mathrm{na}$ & 0 \\
\hline HW-12 & 16 & 0 & uk & uk & na & 0 \\
\hline HW-13 & 22 & 0 & 0 & 0 & na & 0 \\
\hline HW-14 & 38 & 1 & 0 & 0 & 5.8 & 0 \\
\hline HW-15 & 32 & 2 & 0 & 0 & 11.5 & 0 \\
\hline HW-16 & 31 & 0 & 0 & 0 & na & 0 \\
\hline HW-17 & 62 & 2 & 0 & 0 & 39.1 & 0 \\
\hline HW-18 & 53 & 0 & 0 & 0 & na & 0 \\
\hline HW-19 & 59 & 1 & 0 & 0 & 30.2 & 0 \\
\hline $\mathrm{HW}-20$ & 46 & 2 & 0 & 1 & 14.2 & 0 \\
\hline HW-21 & 37 & 0 & 0 & 0 & na & 0 \\
\hline HW-22 & 47 & 0 & 1 & 0 & uk & 1.8 \\
\hline HW-23 & 58 & 2 & 0 & 1 & uk & 0 \\
\hline
\end{tabular}

healthy women $(\mathrm{n}=11)$. Among nulliparous women with systemic sclerosis, two had male DNA (18\%) and among healthy women three $(27 \%)$, with all but one healthy women (who had an induced abortion) also being nulligravid. Positive results ranged from 0.4 to $23.7 \mathrm{gEq} / \mathrm{mil}$ in women with systemic sclerosis and from 0.7 to $5.1 \mathrm{gEq} / \mathrm{mil}$ in healthy women. None of the women with positive results had a history of blood transfusion or a male twin.

For women who had a pregnancy, the time since the last pregnancy was somewhat greater among women with systemic sclerosis than among healthy women (mean 18.6, median $14.0 v$ mean 14.5, median 11.5); the number of daughters was similar (mean 1.4 and 1.5, respectively). More women with systemic sclerosis than healthy women reported a history of spontaneous abortion (44\% v 14\%). Women with systemic sclerosis were somewhat older when tested than healthy women (mean 47.6, median $49.5 v$ mean 42.6, median 39.0).

For further confirmation of positive results we conducted additional tests from the same woman from different aliquots of DNA (from the same blood sampling) and from different blood samplings. Some women without a history of spontaneous or induced abortion had positive results in multiple wells from different blood samplings (SS-10, SS-16, and HW-10) and from additional assays conducted on other dates (SS-08) (data not shown), confirming results in tables 1 and 2. The median DNA equivalent total number of cells tested was similar between women with systemic sclerosis (median: $129358 \mathrm{gEq}$ ) and healthy women (128 $430 \mathrm{gEq}$ ).

In the overall study population male DNA was sometimes found in women who had given birth to daughters but had no history of previous pregnancy, women who had never given birth but had a previous induced abortion, and also among women with no history of any previous pregnancy. Although we did not find male DNA in any woman who only had a history of previous spontaneous abortion in our study, testing for male DNA would not detect microchimerism from a female fetus. We were able to conduct a QPCR test for a non-shared HLA polymorphism of the husband to test one woman with systemic sclerosis who had five spontaneous abortions, using recently described methods. ${ }^{9}$ High levels of microchimerism with the HLA sequence of the husband were found, supporting the likelihood of persistent fetal microchimerism from previous spontaneous abortions in this case (data not shown).

\section{DISCUSSION}

Recent studies have implicated persistent fetal Mc in parous women with systemic sclerosis. ${ }^{10}$ Most studies investigating fetal Mc in autoimmune diseases have used testing for male DNA (or cells) in women as the measure of persistent fetal Mc, usually testing women known to have previously given birth to a son. This approach is often taken not because of a proposed biological difference in fetal Mc from sons compared with daughters, but rather for the technical reason that a single assay can be used to test many women. Former studies, however, have not specifically examined the potential for sources other than a previous male birth to lead to persistent male DNA in a woman. Therefore, in the current study we asked whether male DNA can be found in peripheral blood mononuclear cells of women who had no history of a male birth. We employed a previously developed real time quantitative PCR assay for a Y chromosome sequence to test women with systemic sclerosis and healthy women with no previous birth of a son. ${ }^{8}$

We found that male DNA was not uncommon in the circulation of women who had not given birth to a son. Male DNA was found in $14 \%$ of women overall, with no significant difference between women with systemic sclerosis and healthy women. The lack of a difference between systemic sclerosis and healthy women does not argue against previous reports implicating fetal Mc in systemic sclerosis. Rather, our results indicate that any positive result attributable to male DNA originating from other than a previous male birth would be expected to be similar in women with systemic sclerosis and healthy women. It does indicate, however, that the term "exogenous" may be more appropriate than "fetal" when Mc is assessed by testing for male DNA, and that the specific origin of all sources of male DNA in women requires further investigation. 
There are at least four potential explanations for male DNA in a woman with no history of a male birth. As a first possibility, male DNA could originate from a pregnancy that was not carried to term. It has been assumed that persistent fetal Mc can result from a spontaneous or induced abortion. High levels of male DNA have been reported in women undergoing elective pregnancy termination. ${ }^{6}$ Consistent with this observation, in the current study we found male DNA in two of three women who had a history of induced abortion. A previous spontaneous abortion with a male fetus that was unrecognised could result in male DNA. Disproportionately greater loss of males in utero has been proposed as an explanation of the excess male/female ratio at fertilisation compared with that at birth ${ }^{11}$; however, it is unclear whether loss would occur at a sufficiently advanced point in pregnancy for fetal cells to have reached the maternal circulation. In a recent review of fetal Mc studies, fetal loss was suggested as potentially important in persistent fetal Mc. ${ }^{12}$

We did not find Mc with male DNA in any of the 14 women reporting a previous spontaneous abortion in our study. However, it is reasonable to presume that persistent fetal Mc could occur after a spontaneous abortion, and testing for male DNA would not detect fetal microchimerism from a female fetus. Lending support to this possibility, one woman in the current studies who tested negatively for male DNA and who had multiple spontaneous abortions did have microchimerism when tested by targeting a non-shared HLA specific sequence of her husband.

Although one woman who had a male twin had a negative result, a second possibility that could apply to other women is that cells from a male twin transferred to a female fetus in utero and the male twin was lost early in gestation. Various studies have described loss of an unrecognised "vanished" twin as not uncommon in healthy pregnancies. ${ }^{13}$ Because women harbour persistent fetal Mc, and because maternal cells are known to reach the fetal circulation, a third possibility is transfer of cells from an older brother through the maternal circulation in utero. Three women with systemic sclerosis with positive results but with no other history of spontaneous or induced abortion had an older brother. A fourth possibility is that Mc with male DNA might sometimes occur from sexual intercourse alone. Further studies with information about sexual history (including the type of birth control methods and so on) are needed to confirm this last possibility.

Our finding of male DNA in women without sons is consistent with another report that used a kinetic quantitative enzyme linked immunosorbent assay to measure male DNA and found positive results in 33\% of women (5/15) with systemic sclerosis and 23\% (19/83) with other connective tissue diseases, ${ }^{14}$ although male DNA was not reported among healthy women without sons in that study $(0 \%, 0 /$ $8)$. The fact that results differed for healthy women could reflect the small numbers of subjects or differences in assays, study populations, drug use, or in the frequency of previous pregnancies with female fetuses, as fetal Mc from a female fetus is undetected in assays that test for male DNA.

\section{Conclusions}

Male microchimerism is not uncommon in the peripheral blood of women who have never given birth to a son. Results were not significantly different in women with systemic sclerosis and healthy women. This observation invites further scrutiny of the origins of male DNA in women without sons. Our results also highlight the need for additional methods to study Mc beyond those measuring male DNA-for example, quantitative assays targeting HLA or other genetic polymorphisms. ${ }^{9}$

\section{Authors' affiliations}

N C Lambert, J M Pang, Z Yan, T D Erickson, J L Nelson, Immunogenetics, Fred Hutchinson Cancer Research Center, Seattle, Washington, USA

A M Stevens, Pediatrics, Children's Hospital and Regional Medical Center, Seattle

D E Furst, Rheumatology, University of California, Los Angeles, USA

We would like to thank the scleroderma registry and Jennifer Brackensick for their contribution to this study. Supported by the Scleroderma Foundation (grant No 007/01) and by $\mathrm{NIH}$ grants Al41721 and AR48084.

\section{REFERENCES}

1 Lo YM, Lo ES, Watson N, Noakes L, Sargent IL, Thilaganathan B, et al. Twoway cell traffic between mother and fetus: biologic and clinical implications. Blood 1996:88:4390-5.

2 Bianchi DW, Zickwolf GK, Weil GJ, Sylvester S, DeMaria MA. Male fetal progenitor cells persist in maternal blood for as long as 27 years postpartum. Proc Natl Acad Sci USA 1996;93:705-8

3 Maloney S, Smith A, Furst DE, Myerson D, Rupert K, Evans PC, et al. Microchimerism of maternal origin persists into adult life. J Clin Invest 1999; 104:41-7.

4 Nelson JL, Furst DE, Maloney S, Gooley T, Evans PC, Smith A, et al. Microchimerism and HLA-compatible relationships of pregnancy in scleroderma. Lancet 1998;351:559-62.

5 De Moor G, De Bock G, Noens L, De Bie S. A new case of human chimerism detected after pregnancy: $46, X Y$ karyotype in the lymphocytes of a woman. Acta Clin Belg 1988;43:231-5.

6 Bianchi DW, Farina A, Weber W, Delli-Bovi LC, Deriso M, Williams JM, et al. Significant fetal-maternal hemorrhage after termination of pregnancy: implications for development of fetal cell microchimerism. Am J Obstet Gynecol 2001;184:703-6.

7 LeRoy EC, Black C, Fleischmajer R, Jablonska S, Krieg T, Medsger TA, et al. Scleroderma (systemic sclerosis): classification, subsets and pathogenesis. J Rheumatol 1988;15:202-5.

8 Lambert NC, Lo YM, Erickson TD, Tylee TS, Guthrie KA, Furst DE, et al. Male microchimerism in healthy women and women with scleroderma: cells or circulating DNA? A quantitative answer. Blood 2002; 100:2845-51

9 Lambert NC, Erickson TD, Yan Z, Pang JM, Guthrie KA, Furst DE, et al. Quantification of maternal microchimerism by HLA-specific real-time polymerase chain reaction: studies of healthy women and women with scleroderma. Arthritis Rheum 2004;50:906-14.

10 Lambert N, Nelson JL. Microchimerism in autoimmune disease: more questions than answers? Autoimmun Rev 2003;2:133-9.

11 Diamond JM. Causes of death before birth. Nature 1987;329:487-8.

12 Khosrotehrani K, Johnson KL, Lau J, Dupuy A, Cha DH, Bianchi DW. The influence of fetal loss on the presence of fetal cell microchimerism: a systematic review. Arthritis Rheum 2003;48:3237-41.

13 Robinson HP, Caines JS. Sonar evidence of early pregnancy failure in patients with twin conceptions. Br J Obstet Gynaecol 1977;84:22-5.

14 Gannage M, Amoura Z, Lantz O, Piette JC, Caillat-Zucman S. Feto-maternal microchimerism in connective tissue diseases. Eur J Immunol 2002;32:3405-13. 